SANTIN, Thais Dagostini; FORTES, Vinícius Borges. Uso de filtros de conteúdo na internet e sua interferência na democracia. Revista Eletrônica Direito e Política, Programa de Pós-Graduação Stricto Sensu em Ciência Jurídica da UNIVALI, Itajaí, v.13, n.1, $1^{\circ}$ quadrimestre de 2018. Disponível em: www.univali.br/direitoepolitica - ISSN 1980-7791

\title{
USO DE FILTROS DE CONTEÚDO NA INTERNET E SUA INTERFERÊNCIA NA DEMOCRACIA
}

USE OF INTERNET FILTERS BUBBLES AND THEIR INTERFERENCE IN DEMOCRACY

\author{
Thais Dagostini Santin ${ }^{1}$ \\ Vinícius Borges Fortes ${ }^{2}$
}

SUMÁRIO: Introdução; 1. A Revolução da Internet; 2 . O uso da Internet na promoção da Democracia; 1.1. Liberdade de expressão: breves apontamentos; 1.2. Manutenção do Espaço Público; 3. Filtros e censura na rede; 3.1. Filtros na internet e a restrição a informações; 3.2. A legislação usada como meio de controle social na internet; Considerações finais; Referências das fontes citadas.

\section{RESUMO}

A internet é considerada um espaço democrático, podendo ser utilizada para promover a participação popular e o exercício da cidadania. Contudo, também pode ser usada para restringir liberdades indivíduas, como a de expressão quando da utilização de filtros de conteúdo por governos. Questiona-se como os filtros de conteúdo na internet interferem na manutenção ou na ruptura do processo democrático na contemporaneidade. Para tanto, demonstra-se a importância da internet e como ela alterou a sociedade e a política contemporânea, analisa-se se a internet pode ser utilizada na promoção e manutenção do processo democrático, e, por fim, verifica-se como os filtros de conteúdo na internet interferem no processo democrático. Utiliza-se o método dedutivo, por meio da técnica de pesquisa bibliográfica. Conclui-se que a internet contribui para a promoção e manutenção do regime democrático quando permite a liberdade de expressão, todavia, ao a utilização de filtros de conteúdos da rede promove a ruptura do sistema democrática, pois impede tal liberdade e fragiliza o exercício da cidadania. Palavras-chave: Internet; Filtros de Conteúdo; Democracia; Liberdade de Expressão

\footnotetext{
1 Advogada, mestranda em direito pela Faculdade Meridional - IMED. E-mail: this_santin@hotmail.com

2 Doutor em Direito pela UNESA/RJ, linha de pesquisa "Direitos Fundamentais e Novos Direitos", Mestre em Direito pela UCS/RS. Advogado com experiência nas áreas Direito e Novas Tecnologias, Direito do Trabalho e Direito Empresarial. Professor da IMED - Faculdade Meridional nas Escolas de Direito e Sistemas de Informação. E-mail: viniciusfortes@imed.edu.br
} 
SANTIN, Thais Dagostini; FORTES, Vinícius Borges. Uso de filtros de conteúdo na internet e sua interferência na democracia. Revista Eletrônica Direito e Política, Programa de Pós-Graduação Stricto Sensu em Ciência Jurídica da UNIVALI, Itajaí, v.13, n.1, $1^{\circ}$ quadrimestre de 2018. Disponível em: www.univali.br/direitoepolitica - ISSN 1980-7791

\section{ABSTRACT}

The internet is considered a democratic space, can be used to promote popular participation and the exercise of citizenship. However, it also can be used to restrict individual liberties, such as freedom of expression, when governments use filters bubbles. It questions how the internet filters bubbles interfere in the maintenance or the rupture of the democratic process in contemporaneity. It demonstrates the importance of the internet and how it has altered society and contemporary politics, it analyzes if the internet can be used in the promotion and maintenance of the democratic process, and, finally, it checks how internet filters bubbles interfere with the democratic process. The method used was the deductive, through bibliographical research technique. It concluded that the internet contributes to the promotion and maintenance of the democratic regime when it allows freedom of expression, however, the use of network content filters promotes the rupture of the democratic system, as it prevents such freedom and the exercise of citizenship.

Keywords: Internet; Filters Bubbles; Democracy; Freedom of Expression.

\section{INTRODUÇÃO}

A internet se faz presente em todas as atividades humanas, inserindo-se no cotidiano das pessoas. Por apresentar inúmeros benefícios e facilidades tornou-se indispensável ao homem. Ainda, ela promoveu mudanças sociais que alteraram os processos econômicos, culturais e políticos, redefinido a estrutura e organização da sociedade. Considera um espaço democrático, em virtude de ser um ambiente participativo e colaborativos, que permite a participação de todos e a liberdade de expressão.

A internet pode contribuir significativamente para a implementação de um regime democrático mais eficaz e participativo. Governos democráticos podem utilizá-la na promoção de serviços, informações e transparência governamental, incentivando o debate e a deliberação pública na busca por soluções a problemas socais, a participação popular e a inclusão social, promovendo a manutenção dos espaços públicos e o exercício da cidadania.

Embora seja um espaço democrático, ela pode ser utilizada para restringir direitos e garantias pessoais, algumas nações interferem na infraestrutura da rede para bloquear o acesso seus a conteúdos, promovendo o controle social e a manutenção de seus regimes políticos. Diante desse cenário, indaga-se como os filtros de 
SANTIN, Thais Dagostini; FORTES, Vinícius Borges. Uso de filtros de conteúdo na internet e sua interferência na democracia. Revista Eletrônica Direito e Política, Programa de Pós-Graduação Stricto Sensu em Ciência Jurídica da UNIVALI, Itajaí, v.13, n.1, $1^{\circ}$ quadrimestre de 2018. Disponível em: www.univali.br/direitoepolitica - ISSN 1980-7791

conteúdo na internet interferem na manutenção ou na ruptura do processo democrático na contemporaneidade. Busca-se analisar como a internet pode interferir na manutenção ou na ruptura do processo democrático, por meio de filtros de conteúdo.

Para tanto, procura-se demonstrar a importância da internet e como ela alterou a sociedade e a política contemporânea, bem como analisar de que modo a internet pode ser utilizada na promoção e manutenção do processo democrático. Ao final pretende-se verificar como os filtros de conteúdo na internet interferem no processo democrático. Utiliza-se o método dedutivo, por meio da técnica de pesquisa bibliográfica, em fontes primarias e secundárias.

\section{A REVOLUÇÃO DA INTERNET}

As tecnologias, especialmente de informação e comunicação, inseriram-se no cotidiano das pessoas, proporcionando inúmeros benefícios. Presentes em todas as atividades, desde as mais simples até as mais complexas, otimizam e facilitam a vida, mudando a forma como o ser humano percebe e se relaciona com o mundo ao seu redor. Seu impacto na sociedade alterou, profunda e significativamente, a estrutura e organização social.

A internet ganha cada vez mais espaço na sociedade contemporânea, tendo em vista as vantagens e possibilidades que oferece, tornando-se indispensável ao homem. Trata-se de uma rede, que conecta inúmeros computadores em todo o mundo, possibilitando a comunicação rápida e instantânea entre as pessoas, maior acesso a informações e ao conhecimento, ganhando relevância econômica e social.

Surge uma nova forma de comunicação que ultrapassa as fronteiras nacional, e não esta ligada a nenhum órgão governamental, bem como um novo modelo de relacionamento, que transformou as estruturas sociais, econômicas, políticas e culturais, tornando a informação o eixo da sociedade. Por facilitar a comunicação e organização social, a internet, proporciona meios para que as pessoas divulguem dados e informações, noticiais, opiniões pessoas, incentivando o debate e a reflexão e colaborando com a participação democrática 
SANTIN, Thais Dagostini; FORTES, Vinícius Borges. Uso de filtros de conteúdo na internet e sua interferência na democracia. Revista Eletrônica Direito e Política, Programa de Pós-Graduação Stricto Sensu em Ciência Jurídica da UNIVALI, Itajaí, v.13, n.1, $1^{\circ}$ quadrimestre de 2018. Disponível em: www.univali.br/direitoepolitica - ISSN 1980-7791

O marco inicial da internet é a ARPANET ${ }^{3}$, uma rede utilizada para fins militares durante a Guerra Fria. Seu desenvolvimento ocorreu rapidamente, principalmente após a criação da World Wide Web (WWW), do NCSA Mosaic ${ }^{4}$, que tornaram a rede flexível e acessível, e pela popularização dos computadores pessoais na década de 80 , acarretando no exponencial crescimento da rede de conexão global 5 .

A grande expansão da internet se deve aos novos meios de comunicação, modelos de negócios e de propagação de informações e dados, que se tornou possível pelo seu maior acesso e flexibilização. Mesmo assim, o conteúdo disposto na internet, era desorganizado, confuso e desorientado, dificultando que os usuários soubessem quais dados eram verdadeiros, importantes e confiáveis ${ }^{6}$, característico da primeira fase da internet.

A internet passou por três fases, a primeira denominada de Web 1.0, corresponde a criação da rede, os sites eram estáticos, sem muita interação com os usuários, composta essencialmente por documentos. A Web 2.0 é a segunda fase, representada pela produção de conteúdo pelo usuário, e pela maior acessibilidade das páginas de conteúdo, que eram voltadas aos internautas. Uma de suas características é o surgimento dos blogs, das redes sociais, dos chats e das mídias colaborativas $^{7}$, que permitiram maior interação entre as pessoas e a rede,

\footnotetext{
3 Trata-se da rede de conexão utilizada pelo governo americano durante a Guerra Fria. Essa rede funcionada como um sistema de codificação de mensagens, que as dividia em pequenos pacotes de dados. Em cada pacote havia um pedaço da mensagem original, o endereço do destinatário e as informações necessárias para decodificação e remontagem dessa. Pode ser acessado em: (http://www.techtudo.com.br/artigos/noticia/2013/04/internet-completa-44-anos-relembrehistoria-da-web.html).
}

${ }^{4}$ O NCSA Mosaic foi o software desenvolvido para facilitar a navegação na internet.

5 VASCONCELOS, F. A. de. Internet: a responsabilidade do provedor pelos danos praticados. Curitiba: Juruá, 2005.

${ }^{6}$ FORTES, V. B. Os direitos de privacidade e a proteção de dados pessoais na internet. Rio de Janeiro: Lumen Juris, 2016.

7 VICENTIM, J. Web 1.0, Web 2.0 e Web 3.0... Enfim, o que é isso? EX2 Agência Digital, 2013. Disponível em: <http://www.ex2.com.br/blog/web-1-0-web-2-0-e-web-3-0-enfim-o-que-e-isso/> . Acesso em 02 jan 2017. 
SANTIN, Thais Dagostini; FORTES, Vinícius Borges. Uso de filtros de conteúdo na internet e sua interferência na democracia. Revista Eletrônica Direito e Política, Programa de Pós-Graduação Stricto Sensu em Ciência Jurídica da UNIVALI, Itajaí, v.13, n.1, $1^{\circ}$ quadrimestre de 2018. Disponível em: www.univali.br/direitoepolitica - ISSN 1980-7791

facilitando a difusão, edição e publicação de conteúdo ${ }^{8}$, bem como popularizando a internet.

Representa um ambiente colaborativo, onde a inteligência coletiva é a base. Também é marcada pela dinamicidade dos sites e pelas páginas de busca inteligentes, principalmente o Google, que se transformou no líder de mercado. Iniciou-se a exploração econômica, especialmente por empresas que a utilizaram para criar modelos de negócios e de desenvolvimento ${ }^{9}$. A última fase é Web 3.0 que configura os princípios para a criação de uma base de conhecimento semântico e qualitativo, pois armazena as preferências dos usuários, combinando-as com o conteúdo já existente. Assim, atende-se as demandas de informação com maior precisão e facilita o acesso aos conteúdos ${ }^{10}$.

As pessoas usam a rede para as mais diversas atividades e em todos os ambientes, tornando a sociedade mais produtiva e dinâmica. Ao mesmo tempo em que cria novas oportunidades, também potencializa as ameaças que pairam sobre a sociedade, deixando-a mais vulnerável ${ }^{11}$. A internet facilita a prática de delitos, bem como, promove o surgimento novos crimes, é o caso do cyberbullying, do sequestro digital ${ }^{12}$ e do sexting.

8 KÜSTER, I; HERNÁNDEZ, A. De la Web 2.0 a la Web 3.0: antecedentes y consecuencias de la actitud e intención de uso de las redes sociales en la web semántica. Universia Business Review, n. 37, p. 104-119, 2013.

${ }^{9}$ O'REILLY, T. What is Web 2.0: Design Patterns and Business Models for the Next Generation of Software O'REILLY, 2005. Disponível em: <http://www.oreilly.com/pub/a/web2/archive/what-isweb-20.html>. Acesso em: 02 jan 2017.

10 KÜSTER, I; HERNÁNDEZ, A. De la Web 2.0 a la Web 3.0: antecedentes y consecuencias de la actitud e intención de uso de las redes sociales en la web semántica. p. 107.

11 GROMOV, G. The Roads and Crossroads of Internet History. NetValley, 2017. Disponível em: <http://www.netvalley.com/intval_intr.html>. Acesso em: 02 jan. 2017.

12 Trata-se do sequestro de bancos de dados ou arquivos digitais, por meio do ransomware, um malware criado para invadir computadores ou telefones e criptografar as informações ali contidas, deixando-as inacessíveis ao usuário. O acesso só é liberado após o pagamento do resgate exigido, que é cobrado em Bitcoin ou MonyPak (espécies de moedas virtuais), evitando que os hackers sejam rastreados. Importante referir que, uma vez criptografados os dados não há mais recuperá-los, a não ser pelo pagamento do resgate. Pode ser acessado em (http://www2.uol.com.br/sciam/noticias/sequestro_de_arquivos_digitais.html) e (https://www.arcon.com.br/blog/ransomware-a-industria-do-sequestro-digital). Acesso em: 03 jan. 2017. 
SANTIN, Thais Dagostini; FORTES, Vinícius Borges. Uso de filtros de conteúdo na internet e sua interferência na democracia. Revista Eletrônica Direito e Política, Programa de Pós-Graduação Stricto Sensu em Ciência Jurídica da UNIVALI, Itajaí, v.13, n.1, $1^{\circ}$ quadrimestre de 2018. Disponível em: www.univali.br/direitoepolitica - ISSN 1980-7791

Os crimes virtuais são cada vez mais comuns, tendo em vista o grande número de pessoas que a utilizam para desenvolver suas atividades. Criminosos invadem computadores e afins, obtendo dados pessoais, principalmente senhas, números de cartão de crédito e contas bancárias. A internet proporciona inúmeros meios de invasão a privacidade, que se incorporou na vida online das pessoas, tendo em vista o acumulo e a importância das informações pessoais que estão digitalizadas e trafegando pela rede.

Diante da relevância dos dados pessoais para a sociedade, investe-se em meios de coletar, processar e armazenar esses. A comercialização de informações tornou-se um negócio altamente rentável, pois essas podem ser utilizadas para melhorias sociais, criação de políticas públicas, desenvolvimento de novos produtos, direcionamento de publicidades, discriminação de pessoas, controle de massas, entre outros. Evidente os motivos que levaram a informação a se tornar o centro da sociedade, bem como o poder que gera a seu detentor.

Os avanços tecnológicos promoveram a vulnerabilidade social e da privacidade, ao mesmo tempo permitem a comunicação rápida e instantânea. Hoje, representam o meio mais utilizado para comunicação, especialmente a internet. Informações e notícias são disponibilizadas constantemente para acesso, nunca a sociedade esteve tão informada quanto agora. Esse informacionalismo, derivado da rede, fundamentou as alterações sociais, econômicas, políticas e culturais. Nessa nova sociedade todos estão conectados em um espaço comum, que é integrado pelos mais variados sistemas.

Embora seja uma rede de comunicação e informação global, mais da metade da população mundial não possui acesso a ela. De acordo com a pesquisa realizada pela International Telecommunication Union (ITU), 3,9 bilhões de pessoas no mundo estão off-line, na sua maioria mulheres, pessoas idosas, menos instruídas e de baixa renda. Questões ligadas a educação e a renda são determinantes para o uso da rede ${ }^{13}$, assim problemas socioeconômicos impossibilitam uma parcela da

13 UNITED NATIONS INTERNATIONAL TELECOMMUNICATION UNION. Measuring the Information Society Report 2016. ITU Committed to Connecting the World, 2016. Disponível em: <http://www.itu.int/en/ITU-D/Statistics/Documents/publications/misr2016/MISR2016-w4.pdf>. Acesso em: 03 jan. 2017. 
SANTIN, Thais Dagostini; FORTES, Vinícius Borges. Uso de filtros de conteúdo na internet e sua interferência na democracia. Revista Eletrônica Direito e Política, Programa de Pós-Graduação Stricto Sensu em Ciência Jurídica da UNIVALI, Itajaí, v.13, n.1, $1^{\circ}$ quadrimestre de 2018. Disponível em: www.univali.br/direitoepolitica - ISSN 1980-7791

população de acessá-la, deixando-as a margem da sociedade e impedindo o adequado desenvolvimento dessa.

Os efeitos e impactos causado pela internet são sentidos por todas as pessoas, inclusive por aquelas que não a utilizam. A sociedade tem sua estrutura e organização alterada por essa ferramenta, as relações hierárquicas de poder foram transformadas em relações verticais, que são inclusivas ou exclusivas ${ }^{14}$. As nações passam a operar a nível nacional e global, pois a rede proporcionou a globalização, alterando as estruturas dos Estados ${ }^{15}$ e a política.

A internet e as novas tecnologias revolucionaram a sociedade, alterando a forma como as pesas se relacionam e se comunicam, disseminando a informação e o conhecimento. A evolução da rede possibilitou seu uso para fins econômicos, transformando-a em uma ferramenta de negócios e comercio, gerando mudanças significativas na economia mundial, visando o aumento do lucro e da produtividade.

A revolução tecnológica deu base para o surgimento de uma nova economia, caracterizada por seu alcance global, flexibilidade e informacionalismo. Esse novo sistema organizado em torno das tecnologias da informação, especialmente da internet, "possibilita que a própria informação se torne produto do processo produtivo ${ }^{16 ",}$, tornando a sociedade mais produtiva e competitiva. Nesse sistema econômico desenvolvem-se novas regras e a tecnologia está em constante evolução e transformação, aumentando produtividade e, consequentemente, a competitividade, que já não é mais local ou nacional.

Cabe ao Estado garantir e incentivar a competitividade de mercados, a fim de que produzam e lucrem mais. A informação desenvolve papel central nesse cenário, tornando-se força produtiva no sistema capitalista ${ }^{17}$, seu processamento e

\footnotetext{
14 MICONI, Andrea. Ponto de virada: a teoria da sociedade em rede. In: DI FELICE, Massimo (Org.). Do público para as redes. São Caetano do Sul, SP: Difusão Editora. p. 145-173. 2008.
}

15 CASTells, M.; CARDOZO, G. A Sociedade em Rede Do Conhecimento à Acção Política. Lisboa: Imprensa Nacional - Casa da Moeda, 2005.

16 CASTELLS, M. A sociedade em rede. São Paulo: Paz e Terra, 2005. p. 119.

17 CASTELLS, M. A sociedade em rede. p. 64/65. 
SANTIN, Thais Dagostini; FORTES, Vinícius Borges. Uso de filtros de conteúdo na internet e sua interferência na democracia. Revista Eletrônica Direito e Política, Programa de Pós-Graduação Stricto Sensu em Ciência Jurídica da UNIVALI, Itajaí, v.13, n.1, $1^{\circ}$ quadrimestre de 2018. Disponível em: www.univali.br/direitoepolitica - ISSN 1980-7791

transmissão são fontes da produtividade e de poder. A capacidade que cada sociedade possui de processar informações, gerando novos conhecimentos e inovações são fatores determinantes para seu desenvolvimento, a informação e o conhecimento são o símbolo da internet e dessa nova era.

A internet proporcionou novas experiências ao homem, tornando-o mais individualista. Todavia, a sociabilidade não é diminuída pelo uso da internet, ao contrário, as pessoas que utilizam essa ferramenta tendem a ser mais sociáveis e possuir maior número de amigos, ao promover a interação entre indivíduos. Ainda, seus usuários são mais ativos social e politicamente, pois envolvem-se mais que os não usuários ${ }^{18}$.

A comunicação molda a cultura da sociedade, com as transformações geradas pela rede ambas foram alteras. Com a comunicação mais rápida, direta e aberta a vida em sociedade tornou-se global, influenciando os valores, símbolos, interesses, crenças, interferindo na cultura de cada povo. A internet promoveu mudanças culturais nas sociedades, que interferiram na forma como essa se expressa e observa os conflitos sociais, atingindo, ainda, os sistemas econômicos e políticos ${ }^{19}$.

A internet tornou a comunicação mais dinâmica, interativa e digitalizada, surgindo novas formas de comunicação, principalmente midiáticas. As mídias formam os relacionamentos entre organizações sociais, instituições e as pessoas, enquanto receptores de informações, ainda que cada pessoa forme sua própria opinião. A dinamicidade da comunicação é fundamental na criação do espaço e da opinião pública, que embasam as decisões políticas. O comportamento e as opiniões políticas são formados pela comunicação, assim, sua transformação alterou o processo políticos ${ }^{20}$.

A internet forma um sistema colaborativo e interativo, onde as pessoas possuem liberdades de expressão e opinião e onde encontram informações e conhecimentos 23.

${ }^{18}$ CASTELLS, M.; CARDOZO, G. A Sociedade em Rede Do Conhecimento à Acção Política. p.

19 CASTELLS, M. A sociedade em rede. p. 414.

20 CASTELLS, M.; CARDOZO, G. A Sociedade em Rede Do Conhecimento à Acção Política. p. $23 / 34$. 
SANTIN, Thais Dagostini; FORTES, Vinícius Borges. Uso de filtros de conteúdo na internet e sua interferência na democracia. Revista Eletrônica Direito e Política, Programa de Pós-Graduação Stricto Sensu em Ciência Jurídica da UNIVALI, Itajaí, v.13, n.1, $1^{\circ}$ quadrimestre de 2018. Disponível em: www.univali.br/direitoepolitica - ISSN 1980-7791

necessários para formar suas opiniões. Ela constitui um espaço democrático, que permite o exercício da democracia, por meio da participação popular. Algumas nações já perceberam o potencial da rede, e estão utilizando-a para fins políticos, enquanto outras tentam interferir e controla-la.

\section{O USO DA INTERNET NA PROMOÇÃO DA DEMOCRACIA}

A internet e as tecnologias da informação e da comunicação (TICs) tem o potencial de contribuir para a melhora do sistema democrático. A rede é um sistema colaborativo e participativo, onde as pessoas criam e compartilham conteúdos, opinam sobre os mais variados assuntos, desenvolvendo a interação entre os indivíduos e desse com os demais atores que a utilizam. Ela permite a liberdade de expressão, além de criar ambientes de relações entre seus usuários, podendo ser utilizada por governos para promover a participação popular e democrática.

A liberdade de expressão e de opinião é fundamental para a efetiva participação das pessoas na política e para a promoção da democracia. A internet oferece ao cidadão informações e conhecimento suficiente para formar e embasar suas opiniões, além de meios para expressá-las. Podendo ser utilizada com um meio de inclusão social, pois todos podem usa-la e participar desse processo, dede que possuam acesso à rede, para isso investimento em infraestrutura são essenciais. Consolida-se, portanto, como uma ferramenta que permite a participação plural da sociedade.

A promoção de uma cultura democracia se dá através da liberdade de expressão, que quando inseria na internet é irrestrita e tem o potencial de permitir a participação de todos os cidadãos indiscriminadamente. Através garantia desse direto as pessoas podem participar da criação, propagação e crescimento dessa cultura, por meio do desenvolvimento de ideias e valores que constituem a sociedade. Tal cultura corresponde a liberdade de expressão e a autonomia coletiva, isto é, a forma como cada indivíduo participa da produção e distribuição da cultura e dos valores de cada sociedade ${ }^{21}$.

${ }^{21}$ BALKIN, J. M. Digital Speech and Democratic Culture: a Theory of Freedom of Expression for the Information Society. New York University Law Review, New York, v. 79, n. 01, 2004. 
SANTIN, Thais Dagostini; FORTES, Vinícius Borges. Uso de filtros de conteúdo na internet e sua interferência na democracia. Revista Eletrônica Direito e Política, Programa de Pós-Graduação Stricto Sensu em Ciência Jurídica da UNIVALI, Itajaí, v.13, n.1, $1^{\circ}$ quadrimestre de 2018. Disponível em: www.univali.br/direitoepolitica - ISSN 1980-7791

As pessoas podem utilizar a internet para inserirem-se no espaço público das sociedades, ela representa o instrumento ideal para isso. Em virtude de ser um ambiente livre e com pouco controle, onde as pessoas pode exercer seus direitos e liberdades, sem que sejam tolhidas pelo Estado, em tese, a rede de conexão mundial representa um meio de debate e deliberações populares. A quantidade infinita de informações ali contidas, a comunicação instantânea, o compartilhamento de conteúdo e a transparência que ela proporciona desenvolvem a inteligência coletiva da sociedade.

Para Levi"22, a inteligência coletiva "é uma inteligência distribuída por toda parte, incessantemente valorizada, coordenada em tempo real, que resulta em uma mobilização efetiva das competência". Essa é característica da rede, que permite o compartilhamento de ideias, conhecimentos, valores e experiências, assim, a sociedade cria uma nova inteligência global, que se encontra em constante desenvolvimento e evolução.

Ao utilizarem a internet e as tecnologias de informação e comunicação (TICs), os governos criam espaços interativos, cooperativos e descentralizados que contribuem para a harmonização desses com os cidadãos. Os governos eletrônicos possibilitam o exercício da cidadania e ampliam a participação democrática, melhorando a prestação de serviços públicos e processos administrativos, aumentando a transparência, a eficiência e a integração entre os órgãos governamentais. Alterando a forma como o governo interagem com a população, empresas e demais governos, bem como é um meio de combate à exclusão digital ${ }^{23}$.

Essa forma de governo vale-se das TICs, principalmente da internet, para prestação de serviços públicos. Essas tecnologias servem de elo entre os governos e os cidadãos, promovendo meios para que o governo forneça informações e

\footnotetext{
22 LEVY, P. A Inteligência Coletiva - Por uma antropologia do ciberespaço. São Paulo: Editora Loyola,1998. p. 28.

23 BARBOSA A.; GETSCHKO D.; GATTO R., Internet e Cidadania: A Importância dos Espaços Virtuais no seu Exercício. In: COMITÊ GESTOR DA INTERNET NO BRASIL. Pesquisa sobre o uso das tecnologias da informação e da comunicação no Brasil 2005 - 2009. São Paulo: Comitê Gestor da Internet no Brasil, p. 77-85, 2010.
} 
SANTIN, Thais Dagostini; FORTES, Vinícius Borges. Uso de filtros de conteúdo na internet e sua interferência na democracia. Revista Eletrônica Direito e Política, Programa de Pós-Graduação Stricto Sensu em Ciência Jurídica da UNIVALI, Itajaí, v.13, n.1, $1^{\circ}$ quadrimestre de 2018. Disponível em: www.univali.br/direitoepolitica - ISSN 1980-7791

serviços à população ${ }^{24}$, tornando sua atuação mais transparente e eficaz. A rede conecta os cidadãos em tempo real, garantindo a participação desses na política, por isso é necessário difundi-la. Apenas com a participação de todas as pessoas assegurada, será possível a criação de um efetivo estado democrático ${ }^{25}$. Assim o governo eletrônico oportuniza a participação das pessoas no processo democrático, aumenta a responsabilidade governamental e dos cidadãos, melhora a prestação de serviços e informações públicas, aumentando a transparência governamental.

Para que isso ocorra, é necessário que sejam desenvolvidas políticas públicas que atendam às necessidades da população e garantam a inclusão social. A internet pode ser utilizada como ferramenta de comunicação e interação entre os atores políticos, onde a sociedade expõe seus anseios e o governo procura solução para os mesmos. Ainda, é possível que a população ofereça as soluções, por meio de debates e deliberações, novamente a rede é a ferramenta ideal, disponibilizando espaços e promovendo a participação popular e democrática.

A internet pode ser utilizada como um meio de comunicação entre governos e seus cidadãos, permitindo a interação entre os diferentes atores políticos e sociais. Promove o envolvimento das pessoas com o governo, o exercício da cidadania, o debate político, a participação pública e democrática e a inclusão social, desde que seja utilizada como meio de empoderamento da sociedade. Mas para isso não basta garantir a comunicação instantânea, é necessário, ainda, possibilitar que os cidadãos tenham acesso a informações e possam expressar suas opiniões dentro da rede.

24 BARBOSA A.; GETSCHKO D.; GATTO R., Internet e Cidadania: A Importância dos Espaços Virtuais no seu Exercício. In: COMITÊ GESTOR DA INTERNET NO BRASIL. Pesquisa sobre o uso das tecnologias da informação e da comunicação no Brasil 2005 - 2009. p. 84.

25 MEZZAROBA, M; BIER, C. Revisão sistemática da literatura sobre democracia eletrônica e governo eletrônico. In: ROVER, A. J.; GALINDO F. (Organizadores). III Encontro de Internacionalização do Conpedi. Vol 09. Madrid: Ediciones Laborum, p. 208-232, 2015. 
SANTIN, Thais Dagostini; FORTES, Vinícius Borges. Uso de filtros de conteúdo na internet e sua interferência na democracia. Revista Eletrônica Direito e Política, Programa de Pós-Graduação Stricto Sensu em Ciência Jurídica da UNIVALI, Itajaí, v.13, n.1, $1^{\circ}$ quadrimestre de 2018. Disponível em: www.univali.br/direitoepolitica - ISSN 1980-7791

\subsection{LIBERDADE DE EXPRESSÃO: BREVES APONTAMENTOS}

Com o surgimento da internet e da TICs a liberdade de expressão passa a ser vista sob um novo ângulo, características que anteriormente não era dado a devida importância, tornam-se centrais e objeto de preocupações. Essas tecnologias alteram a forma como o ser humano se expressa e interage na sociedade, ampliando a participação política e cultural do homem. Podendo ser utilizadas, ainda, como meio de participação política, auxiliando na construção de uma sociedade mais democrática.

A internet possibilita que os usuários sejam editores ativos das informações, e não apenas receptores passivos, ao permitir o compartilhamento participativo dessas e colaborando na criação de conteúdos. Os indivíduos podem encontrar informações objetivas e claras, bem como expor seus pontos de vista sobre todos os assuntos, inclusive os mais complexos e conflituosos.

Essa ferramenta tornou-se fundamental no exercício da liberdade de expressão, que inclui a liberdade de procurar, receber e transmitir ideias e informações ${ }^{26}$. Dessa forma garantir a proteção desse direito é fundamental para a implementação de uma sociedade mais inclusiva, participativa e democrática

Assim, a liberdade de expressão ganha maior relevância na sociedade contemporânea, que está cada vez mais conectada. Limitá-la significa impedir a efetiva participação das pessoas na sociedade, que não expressão suas convicções ou não terão uma, pois não encontrarão conhecimentos e argumentos suficientes para construir uma opinião, uma vez que acarreta na limitação das informações e conhecimentos disponíveis.

Além de ser apreciada pela maioria da população, a liberdade de expressão é um importante instrumento político democrático, ao reforçar a participação das pessoas na política. A democracia indiana enfrenta sérios problemas de ordem

\footnotetext{
26 UNITED NATION HUMAN RGHTS. Report of the Special Rapporteur on the promotion and protection of the right to freedom of opinion and expression. 2011. Disponível em: <http://www2.ohchr.org/english/bodies/hrcouncil/docs/17session/A.HRC.17.27_en.pdf>. Acesso em: 09 jan. 2017.
} 
SANTIN, Thais Dagostini; FORTES, Vinícius Borges. Uso de filtros de conteúdo na internet e sua interferência na democracia. Revista Eletrônica Direito e Política, Programa de Pós-Graduação Stricto Sensu em Ciência Jurídica da UNIVALI, Itajaí, v.13, n.1, $1^{\circ}$ quadrimestre de 2018. Disponível em: www.univali.br/direitoepolitica - ISSN 1980-7791

social e econômica, contudo a liberdade de expressão não é uma delas, a internet, a opinião pública internacional e a impressa nacional não sofrem censura do governo, ainda que esse seja fortemente criticado por elas ${ }^{27}$. Diferente do que ocorre em outros países, que para manter seus regimes não democráticos censuram a impressa e os conteúdos da web, como é o caso da China.

A proteção dessa liberdade garante a participação cultural dos indivíduos, com isso há uma maior interação entre esses, influenciando um aos outros. Assim, a persuasão faz parte do cotidiano das pessoas e encontra-se presente em todas as falas, ainda que de forma desproposital. A comunicação cultural da sociedade é modificada a todo o momento pelo homem, que a transforma em seus propósitos, por meio da liberdade de expressão. Em um regime democrático as pessoas são livres para apropriar-se de elementos culturais, criticá-los ou criar um novo elemento que poderá ser acrescento a cultura já existente 28 .

O direito à liberdade de opinião é considerado um direito fundamental, bem como facilita a garantia de outros direitos culturais, políticos, econômicos, civis, sociais. Para garantir a proteção desse direito na internet, essa deve ser livre de instrumentos que bloqueiam seus conteúdos, os Estados que se valem disso violam a liberdade de expressão. Quando a rede respeita e incentiva essa liberdade, tem-se a realização de vários outros direitos facilitada ${ }^{29}$ e a inclusão social.

A mídia livre auxilia na efetivação de outras instituições democráticas, como por exemplo, eleições livres e multipartidárias, possibilitando a participação da sociedade na política. Ainda, contribui com a população, ao destacar os verdadeiros problemas sociais e econômicos da nação e divulgar as queixas dessa $^{30}$. A internet permite uma maior divulgação desses problemas, que podem inclusive repercutir internacionalmente, além de contribuir para eleições mais

${ }^{27}$ SEN, A. Glória Incerta: a Índia e suas contradições. São Paulo: Companhia das Letras, 2000.

28 BALKIN, J. M. Digital Speech and Democratic Culture: a Theory of Freedom of Expression for the Information Society. p. 04.

29 UNITED NATION HUMAN RGHTS. Report of the Special Rapporteur on the promotion and protection of the right to freedom of opinion and expression. p. 07.

30 SEN, A. Glória Incerta: a Índia e suas contradições. 
SANTIN, Thais Dagostini; FORTES, Vinícius Borges. Uso de filtros de conteúdo na internet e sua interferência na democracia. Revista Eletrônica Direito e Política, Programa de Pós-Graduação Stricto Sensu em Ciência Jurídica da UNIVALI, Itajaí, v.13, n.1, $1^{\circ}$ quadrimestre de 2018. Disponível em: www.univali.br/direitoepolitica - ISSN 1980-7791

transparente, assim como efetiva a fiscalização governamental. Possibilita, ainda, a efetiva participação popular e democrática, denota-se que a pessoas estão mais interessadas em participar ativamente da vida política.

A rede livre de censuras e que respeita a liberdade de expressão, quando utilizada por governos, na promoção de serviços, informações e transparência governamental, permitindo o debate e deliberação pública na busca por solução e a participação de todos os cidadãos, efetiva o exercício da cidadania. A internet, muito tem a contribuir na implementação de uma democracia mais eficaz e participativa, mas para isso é fundamental que ela garanta a liberdade de expressão.

\subsection{MANUTENÇÃO DO ESPAÇO PÚBLICO}

É no espaço público que o homem exerce sua liberdade, por meio de discursos, expressando suas opiniões, assim esse espaço deve ser organizado politicamente. Igualmente dever permitir a liberdade de expressão, o exercício das faculdades humanas e a interação, criando relações pessoais e políticas. Aqui desenvolve-se a política, determinando o futuro da sociedade, assim, é necessário que os cidadãos ingressem nesse espaço.

O espaço público deve permitir a participação de toda a coletividade, que irá debater sobre os problemas que assolam a sociedade na busca por soluções efetivas. O debate é fundamental para a inserção do homem nesse espaço, permitindo uma maior participação popular e democrática, através do consenso popular.

Na sociedade contemporânea denota-se um empobrecimento do espaço público, uma vez que o agir político encontra-se fragilizado diante do condicionamento do comportamento humano. A esfera pública choca-se com a privada, tornando-se impossível distingui-las, a política fica em segundo plano. Tal situação possibilita mecanismos de dominação por regimes não democráticos ${ }^{31}$.

31 GADENZ, D. LA RUE, L. A. A ocupação do espaço público: a participação do indivíduo através da internet. Derecho y Cambio Social, Lima, v. 11, n. 35, p.1-19, 2014. 
SANTIN, Thais Dagostini; FORTES, Vinícius Borges. Uso de filtros de conteúdo na internet e sua interferência na democracia. Revista Eletrônica Direito e Política, Programa de Pós-Graduação Stricto Sensu em Ciência Jurídica da UNIVALI, Itajaí, v.13, n.1, $1^{\circ}$ quadrimestre de 2018. Disponível em: www.univali.br/direitoepolitica - ISSN 1980-7791

É através do espaço público as pessoas transformam o local em que vivem, podendo contribuir para o desenvolvimento da sociedade ou não. Conforme Arendt ${ }^{32}$, o discurso possibilita a participação democrática dos cidadãos no espaço público, permitindo a liberdade pública. É pelo debate que a sociedade encontra soluções para seus conflitos e determina quais são seus interesses, procurando atender as necessidades de todos.

Assim, a liberdade de expressão é fundamental para o espaço público, sem ela esse se torna vazio e sem sentido. Para que possa haver o debate é necessário que as pessoas tenham opiniões e possam expressá-la, a informação é indispensável para a formação do ponto de vista. Nesse sentido, a internet colabora, novamente, com a sociedade, ao promover acesso a informações e conhecimentos, bem como oportuniza espaços para que os debates ocorram, promovendo o exercício da cidadania.

Sem informação as pessoas não exercem de modo aquedado a cidadania, pois ela é essencial para a solução de questões sociais. $O$ acesso a informação permite o debate público e resolução de problemas de modo participativo e democrático entre todo os grupos da sociedade ${ }^{33}$. As TICs, principalmente a internet possibilitam a participação de toda a população, ao potencializar a comunicação e ação política.

O debate dos problemas sociais ocorre no espaço público, assim, as pessoas devem ter acesso a informações para que possam formar suas opiniões e leva-las a discussão social, sem medo de represálias, e podendo exercer a liberdade de opinião em sua plenitude. Dessa forma, a manutenção do espaço público possui grande importância para o exercício da cidadania, pois quando esse espaço é extinto as pessoas não conseguem expressar-se, impedindo a participação da política e a consolidação de um regime democrático.

32 ARENDT, H. A condição humana. Rio de Janeiro: Forense Universitária, 2005.

33 MEZZAROBA, M; BIER, C. Revisão sistemática da literatura sobre democracia eletrônica e governo eletrônico. In: ROVER, A. J.; GALINDO F. (Organizadores). III Encontro de Internacionalização do Conpedi. p. 212. 
SANTIN, Thais Dagostini; FORTES, Vinícius Borges. Uso de filtros de conteúdo na internet e sua interferência na democracia. Revista Eletrônica Direito e Política, Programa de Pós-Graduação Stricto Sensu em Ciência Jurídica da UNIVALI, Itajaí, v.13, n.1, $1^{\circ}$ quadrimestre de 2018. Disponível em: www.univali.br/direitoepolitica - ISSN 1980-7791

\section{FILTROS E CENSURA NA REDE}

$\mathrm{Na}$ sociedade contemporânea a internet pode ser utilizada como espaço democrático e inclusivo, mas também pode representa meios de restringir as liberdades das pessoas, de controle de informações e dados. Estados democráticos tentam controlar a rede, sob o argumento da segurança nacional, utilizando-se dos avanços tecnológicos para vigilância dos dados. Já nações não democráticas, além dessas técnicas, censuram o conteúdo da web, impedindo o acesso a determinado cites e limitando as informações, procuram, assim, garantir o controle social e a manutenção de seus regimes.

A comunicação rápida e instantânea viabiliza, a ocupação do espaço público, por meio do diálogo virtual, e a promoção da democracia ${ }^{34}$. Assim, ela possui o potencial de mobilizar as pessoas, em favor da garantia de seus direitos ou contra ações ou regimes governamentais. Através da rede são difundidas e organizada manifestações sociais, que podem mobilizar toda a nação em torno de um objetivo. Ativistas utilizam a rede para compartilhar informações e conteúdos, coordenando grandes manifestações, o uso dessa ferramenta potencializa o alcance dessas "revoluções" sociais, que passam a ocorrem em âmbito nacional ou regional, e não mais local.

As redes sociais influenciam significativamente no alcance e importância da manifestação. Permitindo a comunicação instantânea, dinâmica e eficaz entre os atroes envolvidos, bem como, seu poder de difusão é maior, alcançando grande parte da população. Tais manifestação representam uma das formas de liberdade de expressão da população, e utilizar a web para sua promoção é um aumentar seu alcance e efeitos, garantindo a visibilidade dessa ação e possíveis soluções governamentais. Conforme Castells ${ }^{35}$ a revolução é própria da rede, e embora inicie nessa se concretiza com a ocupação física dos espaços públicos, como ruas, praças, prédios públicos, entre outros.

34 GADENZ, D. LA RUE, L. A. A ocupação do espaço público: a participação do indivíduo através da internet. p. 08.

35 CASTELLS, M. A sociedade em rede. p.99/102 
SANTIN, Thais Dagostini; FORTES, Vinícius Borges. Uso de filtros de conteúdo na internet e sua interferência na democracia. Revista Eletrônica Direito e Política, Programa de Pós-Graduação Stricto Sensu em Ciência Jurídica da UNIVALI, Itajaí, v.13, n.1, $1^{\circ}$ quadrimestre de 2018. Disponível em: www.univali.br/direitoepolitica - ISSN 1980-7791

Governos temem a internet, levando a restrições de seu uso, por meio de tecnologias que bloqueiam conteúdos, monitoram e fiscalizam informações, coletando e armazenando dados pessoais, identificam ativistas. Logo, tem-se a criminalização da liberdade de expressão e a adoção de legislações restritivas que justificam essas medidas ${ }^{36}$, possibilitando, assim, controlar o tráfego de informações e dados, violando os direitos e garantias fundamentais.

A adoção de tais medidas limita, e até mesmo destrói o espaço público, difundindo ideias superficialmente lógicas para a sociedade de massas. Acaba-se com esse espaço através da imposição da lógica sobre os princípios e da violência gratuita, assim, as liberdades políticas encontram-se gravemente feridas e violadas, tornando-se quase inexistentes. Esses governos impõe a cultura de medo e da agressividade, onde as pessoas limitam-se a aceitar o que lhe é imposto sem fazer perguntas, tornando possível o controle e a manipulação social.

Em regimes totalitários a ação e o discurso possuem papel central, e através dele os governantes impõe suas ideologias, retirando a capacidade de pensar e questionar das pessoas, além de suas liberdades individuais e políticas. Arentd afirma que esses governos são frágeis, e que só se apoiam em si mesmos, por esse motivo limitam, de forma exponencial, a capacidade das pessoas questionarem, destruindo a consciência crítica do indivíduo ${ }^{37}$.

Diante das potencialidades da internet na promoção de uma sociedade mais democrática e participativa, que utiliza a liberdade de expressão e a rede como meios de exercício da cidadania, governos não democráticos tendem a impor barreira no uso dessa ferramenta. O controle dos meios de comunicação se dá através do uso de filtros e/ou da censura da imprensa, de modo há limitar o acesso a informações e a liberdade de expressão, restringindo o os direitos e garantias individuais e o exercício da cidadania, a fim de manter-se no poder.

\footnotetext{
36 BALKIN, J. M. Digital Speech and Democratic Culture: a Theory of Freedom of Expression for the Information Society. p. 07

37 ARENDT, H. Origens do Totalitarismo: antissemitismo, imperialismo e totalitarismo. São Paulo: Companhia das Letras, 1989.
} 
SANTIN, Thais Dagostini; FORTES, Vinícius Borges. Uso de filtros de conteúdo na internet e sua interferência na democracia. Revista Eletrônica Direito e Política, Programa de Pós-Graduação Stricto Sensu em Ciência Jurídica da UNIVALI, Itajaí, v.13, n.1, $1^{\circ}$ quadrimestre de 2018. Disponível em: www.univali.br/direitoepolitica - ISSN 1980-7791

\subsection{FILTROS NA INTERNET E A RESTRIÇÃO A INFORMAÇÕES}

Inúmeras nações vêm limitando o acesso a conteúdos disponibilizados na internet, por meio de aparatos tecnológicos que interferem na infraestrutura da rede, ou censuram notícias em meios midiáticos. Tais técnicas possuem grandes e graves consequências nas liberdades individuais, especialmente a de expressão, além de fragilizar a democracia, pois impedem o efetivo exercício da cidadania e do debate público.

O governo Chinês, por exemplo, faz uso de filtros que impedem o acesso a determinados conteúdos da web, páginas consideradas inapropriadas ou controversas são bloqueadas ${ }^{38}$. A censura é utilizada para impedir críticas ao governo e deixar seus cidadãos alienados quanto a alguns assuntos. Igualmente o governo se vale a vigilância dos dados da população, violando a privacidade das pessoas. Assim, o Estado garante maior controle social e limita a participação democrática.

Cada vez mais nações restringem o acesso a conteúdos da rede, embasam tal ação na proteção da segurança nacional, da população, das crianças e dos adolescentes, dos direitos de propriedade intelectual e outros. Para tanto se utilizam censura auto regulada ${ }^{39}$, da desmontagem ${ }^{40}$ ou da filtragem da internet, que é a abordagem técnica de controle ao acesso de informações e conteúdos disponíveis

38 REIS, G. V. dos. Direitos Civis e Políticos nos BRICS e África do Sul - Um estudo de Direito Comparado. Rev. Fac. Direito UFMG, Belo Horizonte, n. 58, p.187-218, 2011.

39 Algumas nações promovem a autor censura dos hábitos de navegação dos usuários e das escolhas de conteúdos que são publicados online, por meio da intimidação, da ameaça de ações legais ou da promoção de normas socais. Pode ser acessado em (https://opennet.net/aboutfiltering).

40 A desmontagem ocorre quando os reguladores possuem acesso direto e jurisdição legal sobre os hots de conteúdos da web, exigindo a remoção do conteúdo que consideram ilegal ou inapropriado. Pode ser acessado em (https://opennet.net/about-filteri. 
SANTIN, Thais Dagostini; FORTES, Vinícius Borges. Uso de filtros de conteúdo na internet e sua interferência na democracia. Revista Eletrônica Direito e Política, Programa de Pós-Graduação Stricto Sensu em Ciência Jurídica da UNIVALI, Itajaí, v.13, n.1, $1^{\circ}$ quadrimestre de 2018. Disponível em: www.univali.br/direitoepolitica - ISSN 1980-7791

na Web, podendo ocorrer por meio do bloqueio técnico ${ }^{41}$ ou remoção de resultados de pesquisas ${ }^{4243}$.

O controle de comunicação e informação que tais ferramentas permitem, contribui para o isolamento da população. Sem esse controle regimes políticos não democráticos teriam dificuldades em manter-se no poder, especialmente regimes totalitaristas, pois conforme Arentd ${ }^{44}$, tal controle é vital para sua manutenção.

A democracia deve proteger e garantir os direitos e liberdades individuais, promovendo o bem-estar de toda a população. Todavia, não é fácil saber até onde a liberdade das pessoas não afeta o sistema democrático, isto é, qual o limite da intervenção estatal nessas liberdades, para a promoção do bem social. A solução dessa questão é controversa e polêmica. Mas com certeza bloquear conteúdos da internet ultrapassa qualquer limite, violando a as liberdades individuais.

A percepção, ou a simples desconfiança de que o governo possa estar observando, monitorando ou vigiando as pessoas, constituem motivos suficientes para evitar o acesso a conteúdos que possam ser considerados inadequados, e, principalmente para postar tais materiais ${ }^{45}$. Assim, a liberdade de expressão fica limitada, impedindo a manifestação de outros diretos e formação de opiniões.

Com controle da comunicação e da informação as pessoas não possuem acesso a certos conhecimentos, bem como impossibilita a efetivação da participação popular e democrática. Fragiliza-se, assim, o espaço público, quando esse não é completamente eliminado pelo governo, que induzi formas de pensar e agir nas

41 No bloqueio técnico a página da web fica inacessível aos usuários, normamente ocorrem em Estados em que o controle sobre o site ou a jurisdição direta desse não se encontra nos limites da atuação das autoridades. Há três técnicas de bloquear o acesso a sites: bloqueio de IP, adulteração do DNS e bloqueio de URL usando o Proxy. Pode ser acessado em (https://opennet.net/aboutfiltering).

42 Nessa espécie de filtragem não há o bloqueio do site, mas sim a dificuldade de encontrá-lo. As próprias empresas que fornecem serviços de busca na web omitem sites ilegais ou que possuam conteúdos inapropriados de sues resultados de pesquisa, cooperando com os governos. Pode ser acesso em (https://opennet.net/about-filtering).

43 OPEN NET INTERATIVE. About Filtering. Open Net Interative, 2017. Disponível em: <https://opennet.net/about-filtering>. Acesso em: 10 jan. 2017.

${ }^{44}$ ARENDT, H. Origens do Totalitarismo: antissemitismo, imperialismo e totalitarismo. p. 76.

45 OPEN NET INTERATIVE. About Filtering. p. única. 
SANTIN, Thais Dagostini; FORTES, Vinícius Borges. Uso de filtros de conteúdo na internet e sua interferência na democracia. Revista Eletrônica Direito e Política, Programa de Pós-Graduação Stricto Sensu em Ciência Jurídica da UNIVALI, Itajaí, v.13, n.1, $1^{\circ}$ quadrimestre de 2018. Disponível em: www.univali.br/direitoepolitica - ISSN 1980-7791

pessoas, garantindo o controle social. O debate público torna-se inexistente e irrelevante, acarretando grande rupturas no sistema democrático.

\subsection{A LEGISLAÇÃo USADA COMO MEIO DE CONTROLE SOCIAL NA INTERNET}

Recentemente a China aprovou a lei de segurança cibernética, que restringe, ainda mais, a liberdade de expressão na internet, bem como obriga empresas nacionais e estrangeiras a cooperarem com o governo, em investigações criminais ou em prol da segurança nacional fornecendo dados pessoais de seus clientes ${ }^{46}$. 0 pais que já possuía controle de informações e comunicações, por meio de filtros de acesso de conteúdos, limita ainda mais as liberdades de seus cidadãos, e autoriza legalmente a invasão de dados pessoais, ferindo direitos fundamentais e princípios democráticos. A falta de privacidade não permite o pleno desenvolvimento das pessoas, pois é na esfera privada que a personalidade se desenvolve, além de impedir que elas expressem suas verdadeiras opiniões, eis que dominadas pela cultura do medo.

Nesse Estado as pessoas têm seus direitos civis e políticos restringidos a uma série de fatores, e direitos humanos violados constantemente, pelo controle social que é exercido. De acordo como a Human Rights Whatch, o governo chinês desrespeita os direitos de seus cidadãos, especialmente a liberdade de expressão que é fortemente restringida, por meio da censura e de punições. Embora algumas organizações procurem minar essa censura, seus esforços são em vão, pois o governo investe em novas ferramentas tecnológicas que consolidam a censura novamente, como é o caso do "Great Cannon", que interrompeu os serviços prestados pela GreatFire.org ${ }^{47}$.

Na promoção da censura na internet e restrição da liberdade de expressão a China conta com o sistema governamental intitulado de "A Grande Muralha Virtual da

46 BLOOMBERG NEWS. China Adopts Cybersecurity Law Despite Foreign Opposition. Bloomberg Technology, 2016. Disponível em: <https://www.bloomberg.com/news/articles/2016-1107/china-passes-cybersecurity-law-despite-strong-foreign-opposition>. Acesso em: 12 jan. 2017.

47 HUMAN RIGHT WATCH. World Report 2016. Human Right Watch, 2016. Disponível em: <https://www.hrw.org/world-report/2016/country-chapters/china-and-tibet>. Acesso em: 12 jan. 2017. 
SANTIN, Thais Dagostini; FORTES, Vinícius Borges. Uso de filtros de conteúdo na internet e sua interferência na democracia. Revista Eletrônica Direito e Política, Programa de Pós-Graduação Stricto Sensu em Ciência Jurídica da UNIVALI, Itajaí, v.13, n.1, $1^{\circ}$ quadrimestre de 2018. Disponível em: www.univali.br/direitoepolitica - ISSN 1980-7791

China ${ }^{48 " .}$ Esse software é responsável por tornar páginas de conteúdo da internet inacessíveis aos usuários, nele milhares de sensores são utilizados para impedir o acesso a páginas, cujo conteúdo seja sensível, isto é, julgados inadequado ou impróprio. Ainda, sites de buscas não podem mostrar conteúdos sensíveis e a mídia não pode divulgar notícias consideras controversas pelo governo ${ }^{49}$.

Denota-se, assim, que os direitos humanos na China valem enquanto não forem contrários ao interesse do governo. A dura repressão a liberdade de expressão traz consigo várias consequências aos direitos civis e políticos das pessoas, impedindo a consolidação de um espaço público que permitem o debate popular. Assim, o governo controla todas as informações, as comunicações e, principalmente, a sociedade, mantendo-se no poder.

A internet transformou-se em uma ferramenta fundamental para a sociedade contemporânea, utilizada para todas atividades humanas. Limitar o acesso a seus conteúdos através de filtros representa uma grave violação as liberdades individuais, restringindo o acesso a informações e comunicações e a liberdade de expressão. Prejudica, ainda, o espaço público, que passa a ser dominado pela lógica e indução de pensamentos e ações, impendo que o debate público seja efetivado. Dessa forma a sociedade é controlada por seus governantes, garantindo a manutenção de regimes não democráticos.

\section{CONSIDERAÇÕES FINAIS}

A internet alterou a estrutura e organização social, transformando a informação no eixo da sociedade, ao facilitar a comunicação global. Promoveu mudanças sociais que alteraram os processos econômicos, culturais e políticos. Inserindo-se no cotidiano da sociedade contemporânea, é utilizada em todos os campos humanos, desde atividades mais simples até as mais complexas, tornando-se fundamental para o homem e apresentando inúmeras vantagens e possibilidades.

48 No original: Great Chinese Firewall.

49 REIS, G. V. dos. Direitos Civis e Políticos nos BRICS e África do Sul - Um estudo de Direito Comparado. p. 207. 
SANTIN, Thais Dagostini; FORTES, Vinícius Borges. Uso de filtros de conteúdo na internet e sua interferência na democracia. Revista Eletrônica Direito e Política, Programa de Pós-Graduação Stricto Sensu em Ciência Jurídica da UNIVALI, Itajaí, v.13, n.1, $1^{\circ}$ quadrimestre de 2018. Disponível em: www.univali.br/direitoepolitica - ISSN 1980-7791

As mudanças promovidas na comunicação alteraram significativamente o processo político. A web representa um ambiente participativo, colaborativo e inclusivo, constituindo um espaço democrático. Ele permite a interação entre as pessoas e os demais atores que a usam, a ocupação do espaço público, por meio do diálogo virtual, a liberdade de expressão e o acesso a informações e conhecimentos, assim, pode ser utilizada na promoção da participação popular. Algumas nações já perceberam o potencial da rede, e estão utilizando-a para fins políticos, enquanto outras tentam interferir e controlá-la.

A liberdade de expressão é fundamental para efetivar a participação popular no processo político e na promoção da democracia, reforçando a participação das pessoas na política. Tal liberdade permite a garantia de outros direitos culturais, políticos, civis e sociais, assim, sua proteção é indispensável. A internet é considerada o principal instrumento para o exercício dessa liberdade, motivo pelo qual essa deve ser livre de censuras.

Governos democráticos podem utilizá-la na promoção de serviços, informações e transparência governamental, incentivando o debate e a deliberação pública na busca por soluções a problemas socais, a participação popular e a inclusão social, promovendo a manutenção dos espaços públicos e o exercício da cidadania. A internet, muito tem a contribuir na implementação de uma democracia mais eficaz e participativa.

$\mathrm{Na}$ sociedade contemporânea a internet pode ser utilizada como espaço democrático e inclusivo, mas também pode representa meios de restringir as liberdades das pessoas, de controle de informações e dados, garantindo o controle da sociedade. Inúmeras nações vêm limitando o acesso a conteúdos disponibilizados na internet, por meio de filtros que interferem na infraestrutura da rede, ou censuram notícias em meios midiáticos.

Tais ações tem o objetivo de controlar a informações e a comunicação, limitando direitos e garantias individuais, especialmente a liberdade de expressão. Com esse controle o governo, além de impedir o acesso a certas informações, fragiliza o espaço público, o exercício da cidadania e participação popular. 
SANTIN, Thais Dagostini; FORTES, Vinícius Borges. Uso de filtros de conteúdo na internet e sua interferência na democracia. Revista Eletrônica Direito e Política, Programa de Pós-Graduação Stricto Sensu em Ciência Jurídica da UNIVALI, Itajaí, v.13, n.1, $1^{\circ}$ quadrimestre de 2018. Disponível em: www.univali.br/direitoepolitica - ISSN 1980-7791

Adotar meios que limitam a liberdade de expressão, significar violar as liberdades individuais e os direitos humanos, bem como impossibilitar a implementação do debate público e de um regime democrática. Nações que se valem desses instrumentos buscam meios de controle social, a fim de promover a manutenção de regimes não democráticos.

Dessa forma, o uso de ferramentas de bloqueio aos conteúdos da internet, restringe a liberdade de expressão dos cidadãos, promovendo o controle de informações e social, verifica-se, assim, a ruptura do sistema democrático. A liberdade de expressão é fundamental para a promoção e manutenção da democracia, ao possibilitar o acesso a informações e o debate público. A web possibilita é o espaço ideal para o exercício dessa liberdade, podendo ser utilizada por governos na promoção da cidadania, do debate público, da inclusão social, mas para isso, é necessário que ela seja livre de censuras governamentais.

\section{REFERÊNCIA DAS FONTES CITADAS}

ARENDT, $H$. Origens do Totalitarismo: antissemitismo, imperialismo e totalitarismo. São Paulo: Companhia das Letras, 1989

A condição humana. 10 ed. Rio de Janeiro: Forense Universitária, 2005.

BALKIN, J. M. Digital Speech and Democratic Culture: a Theory of Freedom of Expression for the Information Society. New York University Law Review, New York, v. 79, n. 01, 2004.

BARBOSA A.; GETSCHKO D.; GATTO R., Internet e Cidadania: A Importância dos Espaços Virtuais no seu Exercício. In: COMITÊ GESTOR DA INTERNET NO BRASIL. Pesquisa sobre o uso das tecnologias da informação e da comunicação no Brasil 2005 - 2009. São Paulo: Comitê Gestor da Internet no Brasil, p. 77-85, 2010.

BLOOMBERG NEWS. China Adopts Cybersecurity Law Despite Foreign Opposition. Bloomberg Technology, 2016.2 Disponível em: 
SANTIN, Thais Dagostini; FORTES, Vinícius Borges. Uso de filtros de conteúdo na internet e sua interferência na democracia. Revista Eletrônica Direito e Política, Programa de Pós-Graduação Stricto Sensu em Ciência Jurídica da UNIVALI, Itajaí, v.13, n.1, $1^{\circ}$ quadrimestre de 2018. Disponível em: www.univali.br/direitoepolitica - ISSN 1980-7791

<https://www.bloomberg.com/news/articles/2016-11-07/china-passes-

cybersecurity-law-despite-strong-foreign-opposition>. Acesso em: 12 jan. 2017.

CASTELLS, M.; CARDOZO, G. A Sociedade em Rede Do Conhecimento à Acção

Política. Lisboa: Imprensa Nacional - Casa da Moeda, 2005.

. A sociedade em rede. São Paulo: Paz e Terra, 2005.

FORTES, V. B. Os direitos de privacidade e a proteção de dados pessoais na internet. Rio de Janeiro: Lumen Juris, 2016.

GADENZ, D. LA RUE, L. A. A ocupação do espaço público: a participação do indivíduo através da internet. Derecho y Cambio Social, Lima, v. 11, n. 35, p.1$19,2014$.

GROMOV, G. The Roads and Crossroads of Internet History. NetValley, 2017. Disponível em: <http://www.netvalley.com/intval_intr.html>. Acesso em: 02 jan. 2017.

HUMAN RIGHT WATCH. World Report 2016. Human Right Watch, 2016. Disponível em: <https://www.hrw.org/world-report/2016/countrychapters/china-and-tibet>. Acesso em: 12 jan. 2017.

KÜSTER, I; HERNÁNDEZ, A. De la Web 2.0 a la Web 3.0: antecedentes y consecuencias de la actitud e intención de uso de las redes sociales en la web semántica. Universia Business Review, n. 37, p. 104-119, 2013.

LEVY, P. A Inteligência Coletiva - Por uma antropologia do ciberespaço. São Paulo: Editora Loyola,1998.

MEZZAROBA, M; BIER, C. Revisão sistemática da literatura sobre democracia eletrônica e governo eletrônico. In: ROVER, A. J.; GALINDO F. (Org.). III Encontro de Internacionalização do Conpedi. Vol 09. Madrid: Ediciones Laborum, p. 208-232, 2015. 
SANTIN, Thais Dagostini; FORTES, Vinícius Borges. Uso de filtros de conteúdo na internet e sua interferência na democracia. Revista Eletrônica Direito e Política, Programa de Pós-Graduação Stricto Sensu em Ciência Jurídica da UNIVALI, Itajaí, v.13, n.1, $1^{\circ}$ quadrimestre de 2018. Disponível em: www.univali.br/direitoepolitica - ISSN 1980-7791

MICONI, Andrea. Ponto de virada: a teoria da sociedade em rede. In: DI FELICE, M (Org.). Do público para as redes. São Caetano do Sul, SP: Difusão Editora. p. 145-173. 2008.

OPEN NET INTERATIVE. About Filtering. Open Net Interative, 2017. Disponível em: <https://opennet.net/about-filtering>. Acesso em: 10 jan 2017.

O'REILLY, T. What is Web 2.0: Design Patterns and Business Models for the Next Generation of Software O'REILLY, 2005. Disponível em: <http://www.oreilly.com/pub/a/web2/archive/what-is-web-20.html>. Acesso em: 02 jan. 2017.

SEN, A. Glória Incerta: a Índia e suas contradições. São Paulo: Companhia das Letras, 2000.

REIS, G. V. dos. Direitos Civis e Políticos nos BRICS e África do Sul - Um estudo de Direito Comparado. Rev. Fac. Direito UFMG, Belo Horizonte, n. 58, p.187$218,2011$.

UNITED NATION HUMAN RIGHTS. Report of the Special Rapporteur on the promotion and protection of the right to freedom of opinion and expression. $2011 . \quad$ Disponível em: <http://www2.ohchr.org/english/bodies/hrcouncil/docs/17session/A.HRC.17.27_ en.pdf>. Acesso em: 09 jan. 2017.

UNITED NATIONS INTERNATIONAL TELECOMMUNICATION UNION. Measuring the Information Society Report 2016. ITU Committed to Connecting the World, 2016. Disponível em: <http://www.itu.int/en/ITUD/Statistics/Documents/publications/misr2016/MISR2016-w4.pdf>. Acesso em: 03 jan. 2017.

VASCONCELOS, F. A. de. Internet: a responsabilidade do provedor pelos danos praticados. Curitiba: Juruá, 2005. 
SANTIN, Thais Dagostini; FORTES, Vinícius Borges. Uso de filtros de conteúdo na internet e sua interferência na democracia. Revista Eletrônica Direito e Política, Programa de Pós-Graduação Stricto Sensu em Ciência Jurídica da UNIVALI, Itajaí, v.13, n.1, $1^{\circ}$ quadrimestre de 2018. Disponível em: www.univali.br/direitoepolitica - ISSN 1980-7791

VICENTIM, J. Web 1.0, Web 2.0 e Web 3.0... Enfim, o que é isso? EX2 Agência

Digital, 2013. Disponível em: <http://www.ex2.com.br/blog/web-1-0-web-2-0e-web-3-0-enfim-o-que-e-isso/>. Acesso em 02 jan 2017.

Submetido em: 30/06/2017

Aprovado em: 01/02/2018 